\title{
Student Furniture Design as Behavioral and Local Business Resources
}

\author{
Prabu Wardono, R.Susanto \\ Faculty of Art and Design, \\ Bandung Institute of Technology, Bandung 40132, Indonesia \\ pwardono@yahoo.com
}

\begin{abstract}
Student life is unique as they begin to have more freedom than children in seeking various kinds of needs for living. This study analyzes how students live and work in relation to the need for room furniture, and how small local furniture traders face problems in response to that need. From interviews, questionnaires involving 123 students and the use of descriptive statistic and Chi-square test, it was found that male and female students prefer furniture that is affordable, simple, natural, multifunction and durable, besides light, practical and flexible. A new model was proposed to solve the traders' business problem.
\end{abstract}

Keywords: Living behavior; student room; student furniture; small business

eISSN 2514-751X @ C 2018. The Authors. Published for AMER ABRA cE-Bs by e-International Publishing House, Ltd., UK. This is an open-access article under the CC BY-NC-ND license (http://creativecommons.org/licenses/bync-nd/4.0/). Peer-review under responsibility of AMER (Association of Malaysian Environment-Behaviour Researchers), ABRA (Association of Behavioural Researchers on Asians) and CE-Bs (Centre for EnvironmentBehaviour Studies), Faculty of Architecture, Planning \& Surveying, Universiti Teknologi MARA, Malaysia.

DOI: https://doi.org/10.21834/aje-bs.v3i9.304 


\subsection{Introduction}

Being university students, they experience a period of human development called adolescence. During such transitional period people may have problems in defining their own identity, but they have opportunities to choose what they need and want more than they experienced during childhood. In such period, they tend to value things and environment differently from those of children. (Sahimi, 2010) This practice reflects how parents need to consider an appropriate living environment for their child to live during their study years. The effect of living on or off campus on the student's success in the study seems to encourage researchers. Previous research found that the success of study is not determined whether students live at home or campus, but by how comfortable and healthy a living place is to create a positive emotion to encourage learning. In addition, it also needs to have a room quality that does not cause stress, while allowing students to personalize it. (Clemons et al., 2005) Knowing that environments can affect human behaviour and emotion (Mehrabian \& Russell, 1974), a research done by Joan Meyers-Levy in 2007, found that a room quality influences how the inhabitants think, feel and behave. Stressful environment marked by disorganized setting of workspace and bedroom can occur because of inappropriate furniture, poorly designed furniture or badly use of suitable furniture. This situation may potentially happen because mostly students' room are small, so if the furniture is not well designed it is not easy for them to manage and use the least space effectively to make the room look neat.

In fact, students' need for room furniture may not be easily met because its function can be sophisticated. It should be able to store personal belongings, accommodate various kinds of tasks and divide spaces. Although students' room is usually extremely small, they still need a private space, called primary space by Altman (1975) to separate from secondary and public space, where their guests are welcome. (Taylor \& Stough, 1978) This may apply especially for female users, who may need for a higher degree of privacy than males.

Furthermore, since every individual has a different personality, habits and lifestyle, the room furniture might need to be flexible. The personality factor that determines a character of living space or room is so valuable that Kasmar (1970) proposed an instrument called Environment Description Scale and Laumann and House's (1970) introduced Living Room Checklist as quoted by Gosling et al. (2005). The former method resulted in 66 pairedadjectives that could be used to evaluate the comprehensive spatial components of an interior. As well, Vinsel, Brown, Altman and Foss (1980) explored a method of studying personalization of the student room in dormitory by photographing its walls, measuring the decorated space and analysing the contents based on some categories related to personal belongings, affairs, and values including devotion to the university, high school, and home (Gosling, S.D., 2005). Supporting this study, Gosling et al. (2002) like most of the animals, room occupants leave their marks in various kinds of form like "his character, his biography, his recent history" and occasionally his expectations.

Furniture, as part of room setting apparatus, becomes crucial. In order that it can satisfy student needs, furniture should easily be adaptive. However, although there are lots of good design references, but very limited texts that empirically describe the needs of student furniture for living. 
There are some small furniture stalls around Bandung, West Java, Indonesia that target students as their main market. They sell various kinds of basic affordable bookrack, table and small cupboard. However, after so many years their business still looks undeveloped. In response to this, some research questions are proposed as follows: 1 . Do students have specific needs of room furniture to support their behaviour? 2. What furniture design they prefer to support their needs? 3 . Why are the furniture sellers studied not able to increase sales? Do the furniture sellers have a lack of knowledge about marketing? What model do they need to improve their business?

\subsection{Methodology}

This research employed 123 students of Bandung Institute of Technology aged 19-22, male and female as respondents. Questionnaire was used to gather information of samples' particular attitudes and behaviors. This study aims to study students' living and working behavior. Online survey was applied to deliver questionnaire and get responses from the students. They were participated based on voluntary reason.

Before making questionnaire, we set up a focus group representing the population studied for running some interviews to explore the possible key attitudes related to some daily activities students usually perform in the room such as, leisure, working and studying. This information was then used as a reference for preparing a questionnaire while taking account some secondary information from related literature and previous research findings. Ready questionnaire was also tested to them for clarification before being uploaded to the Internet. Based on the information synthesized from this questionnaire, the furniture specification needed was later defined. This important knowledge was then used as a key basis for the design development stage.

In this action research, we made some prototypes according to the final designs. In the next stage, the students were then asked to judge whether it suits their needs. To analyze the data collected from the first questionnaire, a descriptive statistic was used. This technique is sufficient to sum up the majority of samples describing their needs. To enrich this information a Chi-square analysis was applied to know how significant difference of behavior between female and male samples. Finally, some interviews with furniture traders were also undertaken to identify their problem and propose a proper and preferable business model to improve their business.

\subsection{Results}

To analyze the questionnaire using descriptive statistic, some important clues of how students behave in the room can be clarified, and this is described in the following paragraphs.

Although students that mostly sleep alone $(92 \%)$ do not mind how they sleep, either on the bed without base $(37 \%)$ or any which way $(41 \%)$, but sleeping on the mattress with a divan is most wanted (47\%). Similar to the previous data, students tend not to matter over which table they like to learn $(23.1 \%)$, but they mostly prefer to learn on the table with chair 
(47\%). However, learning on a low table and sitting on the floor $(29 \%)$ or over bed $(25 \%)$ is also quite acceptable. Relevant to this result, students also like studying over bed as $27 \%$ of the samples do it every day.

With regard to the need for storages, students need it for storing clothes $(91 \%)$, books $(88.5 \%)$, stationery $(53.3 \%)$, kitchen utensils $(28.7 \%)$ and others $(25.4 \%)$. As storages seem crucial for student room, the way the students purchase and layout in the room may become important to consider. Therefore, students mostly prefer knockdown furniture (35\%). As mostly students live in a fairly small room they also like stackable furniture (42\%) and foldable $(43 \%)$ which is applicable to a low table $(58 \%)$ or over bed table $(73 \%)$. In terms of finishing quality, students tend to like natural finished furniture (45.9\%) than colored ones $(4.9 \%)$, but this depends on the design (53.3\%). In case of students have no problem with this factor, they like brown $(39.6 \%)$ and white finished furniture $(35.8 \%)$ much better than other colors like black (24.5\%), red $(7.5 \%)$ and blue $(8 \%)$ colored one. Aside from a book and clothes storage, normal height table, low table and over bed table, they also need other furniture like, multi-function storage (71.2\%), mirror (51.3\%) and clothes hanger (40.7\%). Concerning the design aspect, the samples tend to prefer simple $(55 \%)$, light $(43 \%)$, and handy furniture $(23 \%)$. They also like furniture that is easy to layout $(47 \%)$, multifunction $(51 \%)$, durable $(76 \%)$ and affordable (24\%).

Questions also address the time span the furniture the students use during the study. The answer to this is they tend to use it as long as possible (67\%) or still usable (40\%). In terms of students' willing to buy, the study shows that they may buy normal height table $(49 \%)$, book rack (35\%) and clothes storage $(60 \%)$ with the highest price among others. In the case of purchasing period, they tend to need bed (50\%), table (52\%), book rack (45\%), and clothes storage $(54 \%)$ since the first year of study.

When asked whether they like to shop furniture in Tamansari furniture stalls, $33 \%$ of the samples says slightly disagree, $20 \%$ quite disagree and $12 \%$ strongly disagree and only less than $8 \%$ agree to buy it there, because of the design $(60.6 \%)$, quality $(74.5 \%)$, and material and color factor $(59.6 \%)$. However, if they must buy furniture from these shops, they would take low table (84.3\%) to consider the price, function, and the distant location of the shops, as indicated by their response, $75 \%, 45 \%$ and $40 \%$ for the former, the latter and the last respectively. Alternatively they would consider buying higher quality furniture like, book rack $(69.7 \%)$, wardrobe $(60.5 \%)$, normal height table $(54.6 \%)$, divan and low table $(27.7 \%)$ in other shops. They would buy such furniture because of the design $(77.7 \%)$ and quality aspect $(73.6 \%)$.

One of some small furniture traders in Bandung is located in Tamansari street. (See Figure 1) They mostly come from a small city called Garut, West Java, and have been running their business for six years. However, such business tradition has existed around for several decades. They sell furniture including, table, low table, wardrobe, bed and framed mirror in a simple kiosk. The sales are good in a period of new student admission, or when new student apartments are established, but uncertain in other seasons. In terms of furniture item, the good sales only occur to low tables. The traders buy unfinished products from others and do the finishing themselves in their kiosk. 
This research used Chi-square analysis to know whether male and female respondents have different study habit in the room related to the use of low table, normal height table, over bed table, or any other way. The result shows that there is no evidence that males and females are different in the way they use table for studying ( $P$ value is 0.89 ).
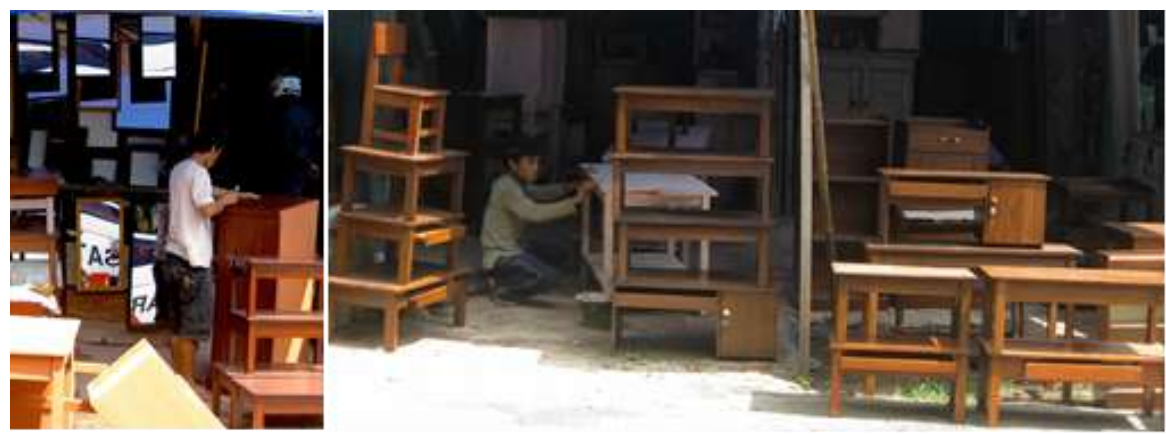

Fig. 1. Local furniture trader at Tamansari street, Bandung

\subsection{Concept development of student furniture and prototype making}

Based on the understanding of student living behavior and problems of finding the right furniture for students, we proposed a new design concept of furniture as follows: 1 . Furniture should apply modular system and consider its dimension with the size of books and files and the need for carrying it by a motorbike. 2. The use of knockdown fitting to ease students during purchasing or moving. 3 . The application of stacking system, especially boxes to help maximize the use of space in the room. 4. The use of cheap boards. Based on these concepts this study developed some prototypes of various racks, including rack $A, B, C, D$ and $E$ illustrated below.

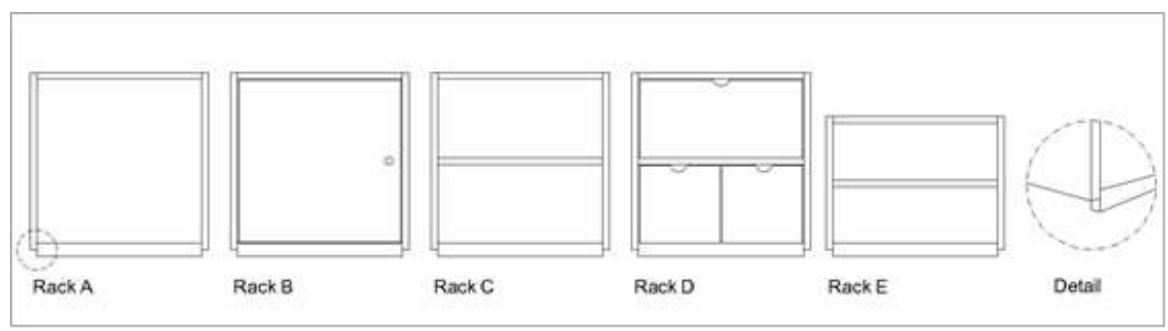

Fig. 2. Rack $A, B, C$ and $D$

All these racks have the same dimension $(\mathrm{H}: 41.5 \mathrm{x} \mathrm{L}: 40 \mathrm{x} \mathrm{W}: 40 \mathrm{~cm})$ and use cheap boards $15 \mathrm{~mm}$. The difference between each of these racks lies on the use of the door and shelf or drawers. The rack $E$ has lower height designed to make the height of two stacking racks even with the table (H:73, L:80, W: $60 \mathrm{~cm})$. 


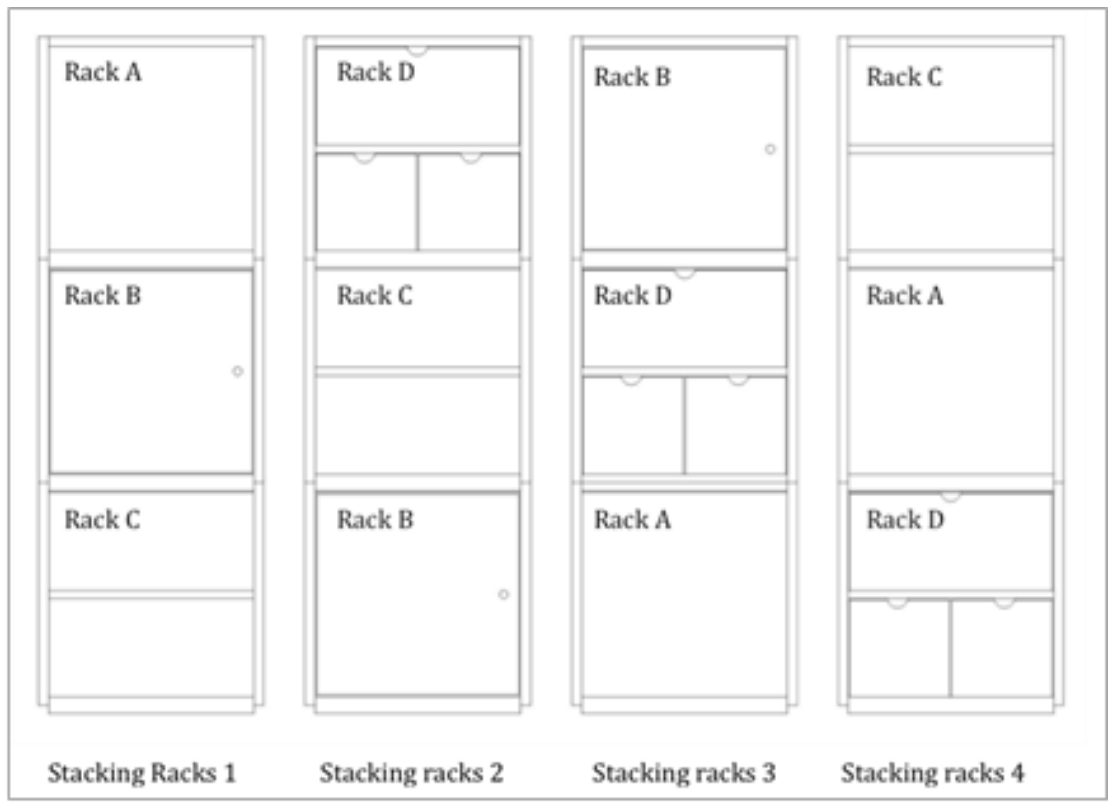

Fig. 3. Possible Stacking racks using Rack $A, B, C$ and $D$

To make sure whether or not this new furniture suits the students' demand, 83 students' preference response towards it are collected again through a survey. The result shows that $47 \%, 43 \%, 33 \%$ of them like the rack $A, B$ and $E$ respectively better than the local furniture of the related items, which only attract $4 \%, 13 \%$, and $20 \%$ of the respondents.

In response to the local traders' business problem, this study proposed a new business model. Cooperation with a design school could be an alternative way to improve their performance. This way helps them to create new designs, develop new products and sell better. With such partnership, the local traders can buy newly developed products from the university while learning how they are initially studied, designed and produced. This project proposed such idea because the furniture apply modular and construction system that needs accuracy. As a consequence, they need specific method and equipment to do it, which may not easily be adopted by the local traders. During this cooperation, the local traders and their carpenter will participate to inspect how new products are designed and produced.

\subsection{Conclusion}

This study results in valuable information on how they behave towards the need for resting and working in the room. This finding also proves the theory that market orientation in product development will uncover more opportunities for business development through segmentation and make a profit from it. (McDonald \& Dunbar, 1998) However, this research 
is limited in how respondents are considered according to residence background. Therefore, in the future such study may need to consider place differences where students live and compare the data between them, for instance between those living in a dormitory and at home. This idea may be relevant to the previous finding that students tend to perform better when living on campus for the first year of their study. (Centre for Applied Economics and Policy Research [CAEPR], 2010) In addition, a direct observation to the room they live may also be needed in the future study in order to add more information collected from the questionnaire, so that more complete picture of problems that students face in the room could be clearly recorded and more effective in the way design responds to it. This finding has also helped us direct a design concept of furniture suitable for students. Many local furniture traders need this idea as they that have no capacity in meeting their targeted market to improve their business. This action research also tries to find a model of how university could play a role in solving small business practitioners' problem dealing with design and product development that exists quite considerably in developing countries, like Indonesia.

\section{Acknowledgement}

This research has been possible because of the financial support from Bandung Institute of Technology, Indonesia, therefore; we would like to express sincere gratitude to them.

\section{References}

Abercrombie, S. (1990). A Philosophy of interior design. New York: Harper \& Row

Center for Applied Economics and Policy Research. (2010). Estimating the effects of dormitory living on student performance (CAEPR working paper \#002-2010). Bloomington, Indiana: De Araujo, P. and Murray, J.

Clemons, S.A. et al. (2005). The Importance of sense of place and sense of self in residence hall room design: A qualitative study of first year. Journal of the First-year Experience and Students in Transition, 17 (2), 73-86.

Gosling, S.D. et al. (2005). The personal living space cue inventory: An analysis and evaluation. Environment and Behavior, 37 (5), 683-705.

Mehrabian, A., \& Rusell, J.A. (1974). An Approach to environmental psychology. Cambridge, MA: M.I.T. Press.

McDonald, M. \& Dunbar, I. (1998). Market Segmentation: how to do it, how to profit from it. London: Macmillan Press.

Taylor, R.B. \& Stough, R.R. (1978) Teritorial cognition: assessing Altman's Typology. Journal of Personality and Social Psychology, 36(4), 418-423. 